\title{
COMMENTARY
}

\section{The Power of Sleep to Transform Learning and Knowledge Retention}

\author{
Daniel R. Malcom, PharmD \\ Sullivan University, College of Pharmacy and Health Sciences, Louisville, Kentucky
}

Corresponding Author: Daniel R. Malcom, Sullivan University, College of Pharmacy and Health Sciences, 2100 Gardiner Ln., Louisville, KY 40205. Tel: 502-413-8969. Email: dmalcom@sullivan.edu

Submitted October 11, 2021; accepted October 19, 2021; ePublished November 2021

Keywords: sleep; learning; memory; well-being

I laid awake one night recently, staring at my ceiling, wondering when my mind would finally shut off and I would be able to fall asleep. A million thoughts raced through my head, most of them related to matters I dealt with at work, though something I watched on television or read during the day may have made an appearance. Regardless, they were unwelcome as I was trying to relax and shut off my brain to sleep. At some point, I began to wonder if I would be able to fall asleep at all. In my own lived experience with sleeping difficulties, this question of whether sleep will ever come during the night is the immediate precursor to that inevitability. This specific night was no different, as that prophecy became self-fulfilling, and I was unable to sleep. The clock continued to tick away through the night into the next morning, and my alarm sounded its siren call to alert me to get ready for the upcoming workday.

For anyone who has experienced insomnia, even temporarily, the feeling of powerlessness as the mind and body fight for dominance is not just frustrating, but also self-defeating as every minute that ticks by reminds the sufferer of the issue and how inescapable it is. According to the National Sleep Foundation, the recommended amount of sleep for adults ages $18-60$ is $\geq 7$ hours per day. ${ }^{1,2}$ Sleep duration of less than 7 hours per day on average is termed "short sleep duration." According to the US Centers for Disease Control and Prevention (CDC), over 1/3 of all Americans (approximately 35\%) report short sleep duration according to 2014 data, the most recent available. ${ }^{3}$ This was less common among those aged $\geq$ 65 (26.3\%), but highest among adults ages 35-44 and 45-54 (38.3\% and 39.0\%, respectively). Closer to traditional collegeaged individuals, those proportions were $32.3 \%$ and $37.9 \%$ (ages 18-24 and 25-34, respectively.

In his recent book Why We Sleep: Unlocking the Power of Sleep and Dreams, Dr. Matthew Walker, a professor of neuroscience and psychology at the University of California Berkeley and director of the Center for Human Sleep Science, details the history of humanity's fascination with sleep and its mysteries. ${ }^{4}$ Modern neuroscience and scientific investigation techniques have been able to elucidate the essential nature of sleep, both in the short-term and long-term, and how sleep affects nearly every facet of our existence, from our internal functions to how we interact with the world around us. One of the key takeaways from the book is how vitally important sleep, specifically high-quality sleep of appropriate depth and duration, is to learning and memory retention. ${ }^{5-9}$ Interestingly, research shows that even on an hour-for-hour basis, time spent in high-quality sleep is more effective for long-term memory than additional study time. Though much is still unknown about sleep, it appears that sleep is where our memories are recorded and organized. ${ }^{10} \mathrm{An}$ apt analogy might be converting a temporary pencil drawing into a permanent ink version that is then indexed and filed according to its themes and potential utility later. Our brains spend our waking time constantly receiving and processing new information, relying on sleep then to make sense of that information. Following this analogy, dreams are thought to be our brains attempting to find associations between the new information and that already known and classified. The resulting scenarios that play out in dreams are our lived experience of this process. This theory would help explain how dreams tend to relate to experiences we have had but incorporate new or novel information into those experiences.

One of the largest and most significant barriers to understanding the impact of sleep and assessing its value is the inherently subjective nature of sleep quality. Comprehensive brain scans or other invasive mechanisms that attempt to objectively evaluate sleep provide only a partial picture of its overall quality and utility in our daily function. One of the most widely used subjective assessments of sleep quality is the Pittsburgh Sleep Quality Index (PSQI), a 19-item self-report instrument that asks respondents to rate the quality of their sleep over the previous one-month period prior to the time the instrument is administered. ${ }^{11}$ Each item in the PSQI belongs to one of seven different domains: daytime dysfunction, habitual sleep efficiency, sleep disturbances, sleep duration, sleep latency, subjective sleep quality, and use of sleeping medication. Each statement is rated by respondents on a frequency scale corresponding to 0-3 points per item. Overall scores on the 
PSQI range from 0-21 with higher scores indicating more acute and significant sleep disturbances. Instrument designers have suggested a cut score of $\geq 5$ on the PSQI as indicative of poor sleep quality. While certainly a helpful tool in evaluating the duration and quality of sleep, assessments like the PSQI are still limited in their ability to detect more intermittent sleep disturbances (ie, affecting perhaps a full week but only every few months) and rely on individual recall of the specific factors which may be limited, particularly in the case of severe sleep disturbances.

Even with the significant shift in focus on student and faculty well-being in recent years, one aspect that has not been as deeply explored is how well our students and faculty members are sleeping and if there are measures we can take to promote sleeping as critical to learning and overall well-being. To date, there have been relatively few assessments of sleep duration and quality in student pharmacists, and none published in pharmacy faculty members. Cates and colleagues surveyed students $(\mathrm{N}=253)$ across three years of a US Doctor of Pharmacy (PharmD) program using the PSQI. ${ }^{12}$ A majority $(55 \%)$ of students who responded to the survey reported a PSQI of $\geq 5$, indicating poor sleep quality, and the overall mean was 6.2 ( $\mathrm{SD}=2.9$ ). Interestingly, the researchers found no significant differences between male and female students in overall PSQI score and found no significant differences in scores among the years in the pharmacy program. However, students in the lowest third of GPA ranges studied (2.00-2.99) had significantly higher scores than students with higher GPAs (Cates 2015). Mnatzaganian and colleagues also assessed sleep quality in student pharmacists $(\mathrm{N}=96)$ across three years of a US PharmD program but administered the assessment twice in the study period (once during a perceived low-stress period and another during a perceived high-stress period. ${ }^{13}$ This study found significant worsening of the PSQI overall scores between low- and high-stress times across all classes, and a significant difference with the third-year group in the study. Sleep duration in mean hours per day ranged from 5.9-6.8, all less than the recommended sleep duration of at least seven hours per day for adults over 18 years of age.

The use of biometrics such as smart watches or other passive monitoring instruments may provide a less invasive way of tracking sleep, though privacy issues exist with any such potentially identifiable information. Nemec et al recently described the use of fitness trackers to assess sleep duration (among other factors) in one cohort of student pharmacists at a single pharmacy program. ${ }^{14}$ Doroudgar and colleagues recently published a study detailing the use of more formal sleep monitoring via actigraphy in a 2021 pilot study including 35 students at one pharmacy program. ${ }^{15}$ Others have tried leveraging technology to "nudge" students to develop and maintain better overall health habits (including sleep), though the systematic use and widespread adoption of effective monitoring and tracking is lacking. ${ }^{16}$

Rather than treating sleep as a necessary evil (or just a required part) of life and something that gets in the way of student learning, we should treat sleep as an indispensable part of the learning process and just as fundamental as attending class and studying or completing activities. Sleep is an essential component in the recipe for student success and should be elevated in our discourse about not just overall well-being, but educational achievement as well. As we discuss changes to curricula and co-curricula to enhance opportunities for students, we should simultaneously be emphasizing and creating the environment in which achieving the optimal period of sleep per day ( $\geq 7$ hours) is attainable.

\section{REFERENCES}

1. Hirshkowitz M, Whiton K, Albert SM, et al. National Sleep Foundation's sleep time duration recommendations: methodology and results summary. Sleep Health. 2015;1(1):40-43. doi:10.1016/j.sleh.2014.12.010.

2. Watson NF, Badr MS, Belenky G, et al.; Consensus Conference Panel. Joint consensus statement of the American Academy of Sleep Medicine and Sleep Research Society on the recommended amount of sleep for a healthy adult: methodology and discussion. Sleep. 2015;38(8):1161-1183.

3. Centers for Disease Control and Prevention. Sleep and Sleep Disorders: Data and Statistics. https://www.cdc.gov/sleep/data_statistics.html. Accessed October 8, 2021.

4. Walker MP. Why We Sleep: Unlocking the Power of Sleep and Dreams. New York, NY: Scribner; 2017.

5. Maquet P. The role of sleep in learning and memory. Science. 2001;294(5544):1048-52. doi: 10.1126/science. 1062856.

6. Diekelmann S, Born J. The memory function of sleep. Nat Rev Neurosci. 2010;11(2):114-26. doi: 10.1038/nrn2762. Epub 2010 Jan 4.

7. Peigneux P, Laureys S, Delbeuck X, Maquet P. Sleeping brain, learning brain. The role of sleep for memory systems. Neuroreport. 2001;12(18):A111-24. doi: 10.1097/00001756-200112210-00001.

8. Walker MP, Stickgold R. Overnight alchemy: sleep-dependent memory evolution. Nat Rev Neurosci. 2010;11(3):218; author reply 218. doi: 10.1038/nrn2762-c1.

9. Cruz T, García L, Álvarez MA, Manzanero AL. Sleep quality and memory function in healthy ageing [published online ahead of print, 2021 Sep 10]. Neurologia (Engl Ed). 2021;S2173-5808(21)00134-6. doi:10.1016/j.nrleng.2018.10.024. 
10. Ulrich D. Sleep spindles as facilitators of memory formation and learning. Neural Plast. 2016;2016:1796715. doi:10.1155/2016/1796715.

11. Buysse DJ, Reynolds CF 3rd, Monk TH, Berman SR, Kupfer DJ. The Pittsburgh Sleep Quality Index: a new instrument for psychiatric practice and research. Psychiatry Res. 1989;28(2):193-213. doi:10.1016/01651781(89)90047-4.

12. Cates ME, Clark A, Woolley TW, Saunders A. Sleep quality among pharmacy students. Am J Pharm Educ. 2015;79(1):Article 9. doi:10.5688/ajpe79109.

13. Mnatzaganian CL, Atayee RS, Namba JM, Brandl K, Lee KC. The effect of sleep quality, sleep components, and environmental sleep factors on core curriculum exam scores among pharmacy students. Curr Pharm Teach Learn. 2020;12(2):119-126. doi:10.1016/j.cptl.2019.11.004.

14. Nemec EC 2nd, Thomas MC, Gile KJ, Tong J, Mattison MJ. Examining the relationship between biometric indicators and pharmacy students' academic performance. Am J Pharm Educ. 2020;84(5):Article 7683. doi:10.5688/ajpe7683.

15. Doroudgar S, Talwar M, Burrowes S, Wang J, Perry PJ. Use of actigraphy and sleep diaries to assess sleep and academic performance in pharmacy students. Curr Pharm Teach Learn. 2021;13(1):57-62. doi:10.1016/j.cptl.2020.08.009.

16. Cain J. Effectiveness of Issuing Well-being challenges to nudge pharmacy students to adopt well-being protective behaviors. Am J Pharm Educ. 2020;84(8):Article 7875. doi:10.5688/ajpe7875. 